\title{
IN HOC LIBRO CONTINENTVR
}

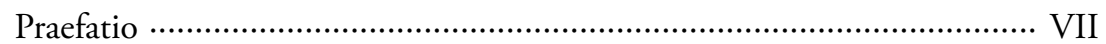

Codicum laterculum …….......................................................... IX

De scholiis Platonicis ……...................................................... XXVII

De Michaele Psello ……........................................................... XXXII

De librorum necessitudinibus ……............................................. XXXIII

De locis aliorum scriptorum ab Hermia allatis ………...................... XL

De Platonis exemplari ab Hermia adhibito ………........................... XLI

De Hermiae editionibus ……….............................................. XLV

Stemma …....................................................................... XLVIII

Haec editio ……....................................................................... XLIX

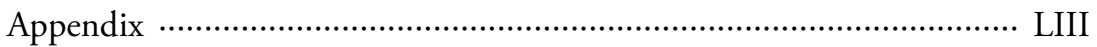

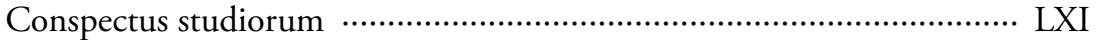

Hermiae editiones ……........................................................... LXI

Hermiae translationes ……....................................................... LXII

Scholiorum in Platonem editiones ……......................................... LXII

Ceterae editiones adhibitae ....................................................... LXIII

Dissertationes quae ad Hermiam praecipue spectant nominaque

virorum doctorum quae in adnotatione critica inveniuntur ........... LXVI

Conspectus siglorum …………………………………................ LXIX

\section{EPMEIOY $\Phi I \Lambda O \Sigma O \Phi O \Upsilon$ \\ TA EI $\Sigma$ TON $\Pi \Lambda$ AT $\Omega$ NO $\Sigma$ $\Phi A I \Delta$ PON $\Sigma$ XO $\Lambda$ IA}

$\mathrm{A}^{\prime}$

$\mathrm{B}^{\prime}$

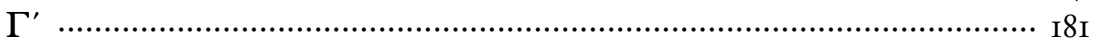

Indices

Index nominum rerumque grammaticalium notabiliorum ….................... 28I

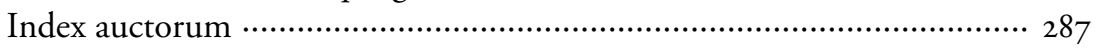

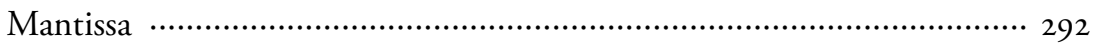


